\title{
INTERNACIONALIZAR OU NÃO, EIS A QUESTÃO? \\ ENSAIO SOBRE A ABANNE/REA
}

\author{
MÍSIA LINS REESINK ${ }^{1}$
}

\begin{abstract}
RESUMO
Este ensaio põe em questão a razão que fundamenta o movimento de transformar a ABANNE em REA, razão esta que 0 justifica pela necessidade de sua internacionalização. Questionando se internacionalizar é preciso, e se isto deve ser feito de qualquer maneira e a qualquer preço, o trabalho propõe olhar para o fenômeno a partir de duas categorias: "espaço político" e "evento", em que a primeira tomaria a ABANNE/REA como tempo/espaço de crítica e luta contra-hegemônica, enquanto a segunda incluiria a ABANNE/REA na lógica de um tempo/espaço apolítico e meritocrático. A proposta defendida aqui é de que a ABANNE/REA deve permanecer atuando, prioritariamente, na lógica do "espaço político", articulada, secundariamente, à lógica do "evento".
\end{abstract}

\section{PALAVRAS-ChAVE \\ ABANNE; REA; Espaço político; Evento; Internacionalização \\ INTERNATIONALIZE OR NOT, THAT'STHE QUESTION? AN ESSAY ABOUTABANNE/REA}

\begin{abstract}
This essay questions the reason in which is based the movement of transforming ABANNE into REA. This reason is justified by the need for its internationalization. Asking if internationalizing is necessary, and if this must be done in any way and at any price, this paper proposes to look at the phenomenon from two categories: "political space" and "event". The first would take ABANNE / REA as a time / space of criticism and counter-hegemonic struggle, while the second would include ABANNE / REA in the logic of apolitical and meritocratic time / space. The proposal defended here is that ABANNE / REA should continue to act, mainly, in the logic of "political space", secondarily articulated to the logic of "event".
\end{abstract}

\section{KEYWORDS}

ABANNE; REA; Political space; Event; Internationalization

\section{INTERNATIONALISER OU PAS, C'EST LA QUESTION? UN ESSAI SUR LA ABANNE/REA}

\begin{abstract}
RÉSUMÉ
Cet essai interroge la raison sous-jacente du mouvement pour transformer ABANNE en REA. Il s'agit de la nécessité de l'internationalisation. En posant la question si l'internationaliser est nécessaire, et si cela doit être fait à tout prix, cet travail propose de regarder le phénomène à partir de deux catégories: «l'espace politique» et «événement» dans lequel le premier prendrait ABANNE / REA comme lieu de critique contre-hégémonique, tandis que la seconde comprendrait ABANNE / REA dans la logique d'un lieu apolitique et méritocratique. La proposition
\end{abstract}

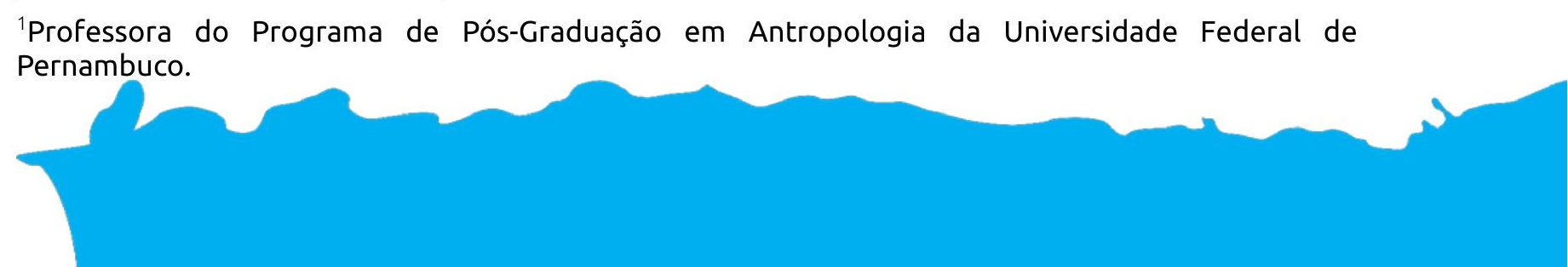


présentée ici est que ABANNE / REA devrait rester en travaillant principalement dans la logique du « lieu politique» en dépit de la logique de l ' «événement».

MOTS CLÉS

ABANNE; REA; Lieu politique; Événement; Internationalisation

\section{INTERNACIONALIZAR O NO, ¿ESA ES LA PREGUNTA? ENSAYO SOBRE LAABANNE/REA}

\section{RESUMEN}

Este ensayo cuestiona la razón que fundamenta el movimiento que pretende transformar la ABANNE en REA y que lo justifica con la necesidad de su internacionalización. Al cuestionar si internacionalizar es necesario y si se debe hacer de cualquier manera y a cualquier precio, el documento propone abordar el fenómeno a partir de dos categorías: "espacio político" y "evento". La primera tomaría la ABANNE / REA como el tiempo/espacio de crítica y de lucha contra hegemónica, mientras que la segunda incluiría la ABANNE / REA en la lógica de un tiempo/espacio apolítico y meritocrático. La propuesta aquí defendida es que la ABANNE/ REA continúe actuando principalmente dentro de la lógica del "espacio político", articulada, en segundo lugar, a la lógica del "evento".

PALABRAS-CLAVE

ABANNE; REA; Espacio político; Evento; Internacionalización 


\section{Introdução²}

Estaríamos fadados a internacionalizar se quisermos existir? Ou, parodiando Neruda, "internacionalizar é preciso, viver não é preciso"? Se isto se tornou "verdade universal" e, portanto, fato inelutável, deve-se fazê-lo a qualquer preço e de qualquer maneira? O quê realmente significa internacionalizar?

Desde os anos noventa do século XX, mas mais fortemente a partir dos anos 2000, o interesse, investimento e "obrigatoriedade" de internacionalização na academia brasileira vêm aumentando, não estando alheio a isto o campo da Antropologia Brasileira. Se por um lado existe a saudável preocupação de aumentar a qualidade, produtividade e circulação do conhecimento produzido; por outro, é perceptível que a chave "internacionalizar""internacionalizado" também se torna, ou é usada, como elemento ou fator de distinção (nos termos de BOURDIEU,1979), em que internacionalizar/internacionalizado é equalizado à qualidade/elite (e em menor grau à cosmopolitanismo) e o não internacionalizado é, explicita ou implicitamente, equalizado à mediocridade e provincianismo. A expressão mais evidente e concreta desta distinção se expressa nas avaliações das Pós-Graduações pela CAPES, cujo principal critério distintivo para se atingir as notas 7 e 6 é o critério de internacionalização (MOROSINI,2011).

Organizado pela primeira vez em 1985 (Recife-PE), o Encontro de Antropólogos do Norte/Nordeste (ABANNE) completou trinta anos em 2015, quando se realizou a sua décima quarta edição (Maceió-AL). Nestes trinta anos, a ABANNE passou por diferentes processos e diferentes circunstâncias, mas hoje, pode-se dizer que se trata de um espaço consagrado e legítimo no campo acadêmico brasileiro, extrapolando suas implicações regionais, sendo atualmente um evento nacional com pretensões internacionais. É no contexto de busca de estabelecimento de estratégias de internacionalização que em 2007 foi agregada a ABANNE (Reunião de Antropólogos do Norte/Nordeste), em sua décima edição, a REA (Reunião Equatorial de Antropologia).

Nesse sentido, tendo como ponto de partida a relação entre ABANNE (regionalnacional) e REA (internacional), objetivo refletir sobre a inelutabilidade da internacionalização, avaliando seus possíveis ganhos e perdas, articulando esta relação a partir da construção de duas categorias: "evento" e "espaço político"; isto para pensar e tentar apresentar algumas possíveis respostas às indagações acima propostas. O argumento aqui avançado é o de que a ABANNE deve ser tomado primeiramente (e preponderantemente) como "espaço político", em que sua qualidade de "evento" é o seu meio de atuação.

\footnotetext{
${ }^{2}$ Gostaria primeiramente de agradecer ao convite e a oportunidade que a Comissão Editorial me fez e me deu de publicar neste primeiro número. Desejando sucesso e longa vida a esta publicação!
} 
Organizo o texto em 3 partes, além da introdução e conclusão. Na primeira, reflito um pouco sobre o que se compreende e/ou se espera de uma acadêmica internacionalizada; na segunda, faço um breve relato da história da ABANNE e da REA, procurando pensar este processo como ação política, argumentando que, especialmente a partir da REA, há uma inflexão maior em direção da valorização da lógica do "evento" em detrimento da lógica do "espaço político"; na terceira parte, proponho elaborar a compreensão da ABANNE como "espaço político" e não apenas como "evento", quando busco problematizar estas duas categorias, articulando com o desejo/necessidade de internacionalizar.

Este texto tem uma vocação ensaística, em que ideias são mais ou menos organizadas a partir de experiências pessoais e observações feitas (e ouvidas) nas dinâmicas dos encontros, nos "corredores" da academia, em salas de reuniões, nos relatos e histórias contadas por colegas em momentos formais ou informais, tudo isto aliado a leituras e pesquisas que conformaram a minha visão do que entendo ser o "espaço ABANNE". Por isto, trata-se muito mais de um ensaio do que propriamente de um artigo que segue "rigores" acadêmicos. A sua "pequena" ambição, portanto, é o de que ele seja "bom para pensar".

\section{"INTERNACIONALIZAR É PRECISO"}

Como dito acima, há cada vez mais pressões e exigências para que a academia brasileira, suas instituições e seus pesquisadores, se internacionalizem. Рara isto estratégias são elaboradas e desenvolvidas, políticas de indução e investimentos estiveram sendo postas em prática. É certo que a procura por internacionalizar responde a um desejo de ser visto e ouvido, de ser reconhecido como produtor de um conhecimento de qualidade e que produz impactos para além das fronteiras nacionais. É certo ainda, como também já dito, que se considera que uma ciência internacionalizada ganha em qualidade e em circulação, aumentando as chances de que o conhecimento produzido tenha maior e melhor impacto nas sociedades a que se dirigem. É mais certo ainda que no Brasil, e especialmente no campo das ciências sociais, internacionalizar tornou-se um instrumento de luta nas relações de poder, que hierarquizam qualificando e desqualificando as diferentes instituições e pesquisadores, em que o fator geopolítico é aliado ao critério de internacionalização, para reproduzir relações hegemônicas já estabelecidas entre as instituições das diferentes regiões e províncias. É nesse contexto que a ideia e o movimento de transformar a ABANNE (um encontro de alcance regional/nacional) em REA (de pretensões internacionais) se instaura.

Mas, antes de avançar nesse debate, deve-se notar, primeiramente, que o modelo de internacionalização desenvolvido no país (com seus respectivos investimentos e políticas) está prioritariamente localizado nas pós-graduações (LEAL et al, 2015, MOROSINI, 2011). Assim, de maneira mais institucional e estrutural, Morosini (2011) distingue a existência de dois modelos 
de internacionalização do ensino superior: o central - "processo que incorpora uma dimensão internacional, intercultural ou global aos objetivos, função e organização da educação póssecundária" (2011, p. 96); o periférico - que se caracteriza pela presença de atividades internacionais em alguns setores das universidades, prioritariamente na pós-graduação, e que é o modelo brasileiro.

Em seguida, é necessário considerar o que se entende por "internacionalização", e como isto é possível no campo das ciências sociais no Brasil. Como lembra Dwyer, "é preciso dizer que o sentido que se dá à internacionalização depende do contexto. No caso brasileiro, o termo sempre se refere às nossas relações com cientistas sociais e com as Ciências Sociais de outros países. É um processo de, por um lado, importação de saberes e de outro recebimento de alunos e professores e, por outro lado, de exportação de saber, professores e alunos, assim como de cooperação em empreendimentos internacionais" (DWYER, 2013, p. 57-58). Em termos mais técnicos e gerais, Morosini (2011) vai classificar esses movimentos na pós-graduação com os termos de "cooperação internacional inicial" - referente à formação de recursos (circulação de estudantes); "cooperação internacional avançada" - referente à produção conjunta do conhecimento, que segundo a autora, é a forma mais elaborada de cooperação. Além disto, Morosini descreve que estas cooperações se dão em dois eixos diferentes: o vertical, que traduzindo é a relação assimétrica que se estabelece entre os parceiros, inclusive do ponto de vista geográfico, já que a parceria se estabelece mais entre países centrais e periféricos; o horizontal, relações de cooperação mais simétricas entre os parceiros e, do ponto de vista geográfico, parceria estabelecida entre países do eixo sul-sul. Complexificando e superpondo a estas classificações, podemos acrescentar ainda as definições de Dwyer para o caso das ciências sociais brasileiras ${ }^{3}$. Segundo o autor, teríamos dois tipos de internacionalização: a primeira seria a estreita, caracterizada pela relação prioritária com os pares/países próximos, em termos linguísticos e geográficos (por exemplo, através de uma RAM e uma REA); a segunda seria a ampla, que se caracteriza por investir na publicação e interação com os centros de poder.

Pode-se inferir também que há uma relativa diversidade do que se entende por internacionalizar. Mais ainda: há certo grau de dúvida se ser internacionalizado significa a circulação por fóruns internacionais, a formação em algum nível em instituições internacionais, ter trabalhos em publicações internacionais (especialmente em outra língua), ser citado por pesquisadores internacionais, atrair alunos e pesquisadores estrangeiros para a sua instituição, ter coordenação ou participação em cooperações internacionais de projetos de pesquisa.

\footnotetext{
${ }^{3}$ O texto de Dwyer (2013) analise especificamente o campo da sociologia brasileira. Contudo, creio que as suas análises e reflexões podem ser aplicadas ao campo da antropologia brasileira porque me parece que a movimentação deste campo não difere muito - pelo menos em termos estruturais - do que acontece no campo da sociologia. No mínimo, as análises de Dwyer nos servem como analogia para pensar o caso da antropologia.
} 
Enfim, ser internacionalizado parece implicar em uma dificuldade de se definir qual direção se tomar: é estar "presente" no exterior, é ter a "presença" do exterior no seu meio, ou é as duas coisas ao mesmo tempo?

Acresce-se a esta dificuldade o fato de que internacionalizar no campo das ciências sociais, e consequentemente a necessidade de fazê-lo, tem complexidades outras do que aquelas das áreas das ciências da natureza e exatas, de onde o modelo de internacionalização é tirado e imposto. Como discute Fiorin: "A internacionalização está condicionada às especificidades de cada área, com suas diversas culturas de publicação" (2007: 201). Posição esta que é desqualificada pelos integrantes das áreas "duras". Contudo, ele avança que a internacionalização da produção das ciências humanas se depara com dois fatores que diminuem sua capacidade de circular internacionalmente: "a) a cultura de publicação, em que se destaca, em primeiro lugar, a preferência por formatos editoriais distintos das publicações periódicas ou em série; e em segundo, a impossibilidade ou dificuldade de pôr o nome em trabalhos de orientandos ou de colegas; b) a natureza do objeto de estudo construído pelas CHS, que limita e circunscreve a dimensão externa do respectivo impacto, uma vez que o fato de tratar de temas relativos às realidades mais locais, de âmbito definido por fatores espaçotemporais específicos, justifica o reduzido interesse e o pouco empenho de sua difusão em escala internacional" (FIORIN, 2007, p. 202). Além disso, junta-se ainda o fator língua, que não necessariamente quer dizer a incompetência em outra língua, mas a dificuldade de traduzir a diversidade de usos de conceitos específicos tirados de contextos culturais específicos. Como lembra Dwyer, a partir de reflexão de Ortiz, "é impossível desenvolver ciências sociais de qualidade através de recurso a uma língua franca. Para explicar a sociologia que se faz em um país para alguém de outro país é necessário prestar atenção à narrativa e ao desenvolvimento conceitual e situar os dois em seus contextos linguísticos e sócio-históricos" (DWEYER, 2013, p.63). Segundo o autor, se faz então necessário adotar uma estratégia muito mais complexa de internacionalização do que o simplesmente dizer que basta traduzir tudo para uma língua franca.

Discorrer um pouco, e rapidamente, sobre o que se discute sobre internacionalização/internacionalizar é importante porque nos ajuda a entender as razões que levam ao projeto de transformação da ABANNE em REA, ao mesmo tempo que serve para se questionar se essas razões justificam de fato a mudança e se ela atingiria os resultados que se espera dela. O curioso é que não encontrei, nos textos consultados por mim que tratam da internacionalização das ciências humanas brasileiras, qualquer discussão ou menção de impactos dos congressos internacionais realizados no Brasil para a internacionalização do conhecimento e/ou instituições brasileiras. Fala-se sobre a participação dos pesquisadores em congressos internacionais e se estas participações são traduzidas em publicações (por exemplo, DWYER,2013 e LEAL et al, 2015), mas não se sabe se parte dessa participação é em 
congressos realizados em terras brasileiras. Parece, contudo, que a realização de congressos internacionais no Brasil entra implicitamente na lógica da cooperação internacional, mas sem que o como se dá isto e quais os seus impactos sejam discutidos. Tudo se passa, de fato, como se a ideia de participação em congresso internacional implicasse no deslocamento do pesquisador para fora das fronteiras nacionais ${ }^{4}$.

É diante do acima exposto que questiono se de fato internacionalizar através da transformação da ABANNE em REA é uma estratégia adequada, ou mesmo se ela tem alguma eficácia; questionando assim se o que se ganha com isto não seria muito pouco em relação ao que se perderia com a aplicação desta estratégia. Como lembra Fiorin: "Estabelecer uma política para a internacionalização da produção científica significa levar em conta a diversidade, a heterogeneidade, a diferença. Todas as áreas, e principalmente as CHS, precisam aumentar sua internacionalização. Mas é preciso sempre considerar que elas são diversas" (FIORIN, 2007, p.279-280). Analogicamente, não seria o caso de pensar que, diante das diversidades regionais, outras estratégias de internacionalização deveriam ser postas em prática, mesmo (ou em especial) no contexto de um "evento"? Guardemos esta discussão por um momento.

\section{UM POUCO DE MEMÓRIA SOBRE AS NOSSAS REUNIÕES DE ANTROPÓLOGOS DO N/NE}

Idealizado pelo antropólogo Roberto Motta, à época professor da UFPE e pesquisador da Fundação Joaquim Nabuco (FUNDAJ-PE), o primeiro Encontro de Antropólogos do Norte/Nordeste (como foi chamado) na época, aconteceu em Recife, em 1985, como já informado. A motivação maior para a chamada do evento foi a da construção de um espaço que oportunizasse a promoção de uma (maior) visibilidade da produção dos antropólogos do Norte e Nordeste. Nos anos setenta e oitenta, esta produção - assim como o número de antropólogos norte/nordestinos - vinha em um crescendo considerável, crescimento este que não se via representando nos fóruns de discussão da antropologia brasileira, ao mesmo tempo em que a tradição antropológica norte/nordestina estava sendo constantemente desqualificada. O fundamento, portanto, da criação da reunião foi eminentemente político: entre antropólogos das duas regiões, havia já a consciência da existência de relações assimétricas e de dominação em que os antropólogos, as instituições e

\footnotetext{
${ }^{4}$ Apesar de não ficar claramente explícito na literatura consultada, pelos dados discutidos e pelas implicações tiradas pelos autores, considero que para estes - implicitamente - falar em participação em congressos internacionais implica em eventos realizados fora do Brasil. Mas, mais uma vez esclareço que os dados apresentados não permitem qualquer conclusão definitiva sobre a questão.
} 
o conhecimento produzido nestas regiões estavam em uma posição subalterna, ao tempo em que a antropologia produzida no centro-sul instaurava-se como hegemônica ${ }^{5}$.

Importa ainda contextualizar as condições particulares desde movimento de construção de um espaço político de combate às assimetrias dentro do campo antropológico brasileiro. Deve-se, contudo, lembrar que, até a Reunião Brasileira de Antropologia, realizada em 1978, em Recife, as forças políticas dentro do campo da antropologia se organizavam de maneira muito menos assimétrica, em que as antropologias (e antropólogos) da Bahia, Pará e Pernambuco tinham grande força política dentro da Associação, com consequente visibilidade da sua produção ${ }^{6}$.

Naquela reunião, relatada como de alta tensão, houve uma movimentação intensa dos jovens antropólogos (em número crescente) que exigiam uma reforma e renovação da direção da ABA, num movimento que ficou conhecido como dos "jovens contra os velhos". Em um contexto de ditadura militar, o então presidente da ABA, René Ribeiro (UFPE/FUNDAJ) conhecido por suas posições favoráveis ao regime militar, representava o velho e as velhas gerações; sobretudo, representava o autoritarismo em oposição à democracia. Se por um lado, esse movimento demonstrava um real desejo de maior espaço de atuação das novas gerações e de uma aspiração por arejamento e renovação da ABA; por outro, curiosamente, a conquista ou vitória dos jovens sobre os velhos se deu com a eleição de Castro Farias (Museu NacionalUFRJ), um dos fundadores da ABA, seu primeiro presidente e um dos seus membros mais velhos em idade, para a presidência da $A B A^{7}$.

Neste sentido, a RBA de 1978 é um divisor de águas, a partir de quando as antropologias e os antropólogos do Norte e Nordeste perdem força e poder, inclusive, e sobretudo, na sua capacidade de construir narrativas que deem legitimidade e criem espaços de visibilidade no campo da antropologia brasileira. A isto se associava as políticas nacionais

\footnotetext{
${ }^{5}$ Para uma análise deste processo, ver Reesink e Campos, 2014. Neste artigo, as autoras argumentam que foi construído um "complexo mítico" que narra a história da antropologia do Brasil, em que a produção desenvolvida nas "províncias" do Norte/Nordeste é historicamente localizada no passado e contemporaneamente invisibilizada e desqualificada. Ver ainda as reflexões de Maués (1998), Motta (1997), Scott (1997) e Reesink e Campos (2016).

${ }^{6}$ Trata-se mais de uma menor assimetria e não de relações simétricas. Contudo, é fato que as condições de luta entre essas províncias em competição eram bem mais equilibradas do que passou a ser a partir do fim da década de 1970, em que as consequências da reforma do ensino universitário, na década de 1960, vai ser um fator importante nesse aprofundamento das assimetrias. Para uma discussão desses processos assimétricos, ver Motta (1997), Meucci (2009) e Reesink e Campos (2016).

${ }^{7}$ Naquela época, assim como acontece ainda hoje, o processo para a eleição do presidente da ABA nunca se dava através de chapas concorrentes (mesmo que o estatuto permita isto). Curiosamente, parece existir um acordo de cavalheiros, em que uma vez que uma chapa é construída não se apresenta nenhuma concorrente, ou seja: o eleito ou a eleita é conhecido/a antes mesmo da eleição. Assim, em 1978, o acordo de cavalheiros feito tinha como futuro presidente da ABA o professor Napoleão (UFPA), em substituição a René Ribeiro (UFPE/FUNDAJ). Em certo sentido, foi contra este acordo de cavalheiros que outro acordo foi feito para eleger Castro Farias (Museu Nacional-UFRJ), pela segunda vez, como presidente da ABA.
} 
de distribuição dos recursos de educação e pesquisa entre as diferentes regiões - estas de longa data - que se concentravam prioritariamente nas instituições do centro-sul, desequilibrando as condições práticas de competição entre as províncias, que se viam competindo em condições desiguais de produção qualitativa e quantitativa do conhecimento, assim como da sua circulação; ao tempo em que as condições (ou critérios) de avaliação desta produção seriam as mesmas para todas as instituições e pesquisadores ${ }^{8}$. Portanto, com a criação do encontro de antropólogos do N/NE, objetiva-se estabelecer tanto um espaço de visibilidade para a produção acadêmica norte-nordestina, quanto um espaço político de crítica a essas relações assimétricas.

O primeiro Encontro de Antropólogos do Norte/Nordeste contou com a participação de antropólogos representando diferentes estados destas regiões, como também alguns antropólogos do centro-sul, mas tratou-se essencialmente de um evento de pequenas dimensões, em termos quantitativos de participação ${ }^{9}$. Entre este primeiro encontro e o segundo, houve um hiato de 6 anos. Apenas em 1991, novamente realizado em Recife, ocorreu o II Encontro de Antropólogos do Norte/Nordeste. Apesar deste hiato, ou talvez por isto mesmo - já que se produziu uma demanda reprimida, a segunda edição do evento atraiu um número considerável de participantes, com apresentação ou não de trabalhos. Esta edição pode ser ainda considerada como aquela que marca o estabelecimento de um compromisso político-moral e semi-informal entre os antropólogos do Norte/Nordeste em dar continuidade ao encontro - já que não há uma instância formal desses antropólogos que poderia se responsabilizar oficialmente pela realização do evento.

\footnotetext{
${ }^{8}$ É interessante observar o que considera Motta, em um contexto de análise dos 20 anos da Pósgraduação em Antropologia da UFPE (MOTTA,1997): "Entretanto, eu bem sei o quanto é mais fácil sermos perdoados por nossos defeitos, graves como possam ser, do que por nossas qualidades [...]. Assim é que, para ser sincero, eu muitas vezes desconfio que nossas notas baixas resultam do que temos de melhor e mais valioso. [...] Parece que muitas vezes somos prejudicados pelo papel heterodoxo ou unmainline que pensadores e antropólogos do Recife - penso nos Gilberto Freyre e René Ribeiro - desempenharam no contexto nacional e pelo fato de termos ousado surgir como mestrado de modo independente dos representantes do paradigma" (1997, p. 34). O que Motta categoriza como "paradigma" ou "paradigma Lewis/Oliveira" é a implantação e expansão do modelo institution building de pós-graduação em antropologia, financiado pela Fundação Ford e introduzido pela aliança Maybury-Lewis/Cardoso de Oliveira, a partir do Museu Nacional, e que se tornará o modelo hegemônico (MOTTA, 1997).

${ }^{9}$ Um dos principais convidados foi Roberto Cardoso de Oliveira. Curiosamente, foi nesta ocasião que ele apresentou a primeira versão daquele que viria a ser um dos textos constitutivos do "complexo mítico" que narra a história da antropologia brasileira, e que estabelece a nossa invisibilidade e incompetência (ver REESINK e CAMPOS, 2014): trata-se do texto "O que é isto que chamamos de Antropologia Brasileira", publicado na coletânea "Sobre o Pensamento Antropológico", em 1988. Não deixa de ser irônico que um dos primeiros textos que produz uma invizibilização da produção nortenordestina tenha sido inaugurado em um espaço que procurava combater este processo. Contudo, trata-se apenas de uma ironia, pois obviamente que tal "projeto" estava sendo construído anteriormente, assim como o texto em questão.
} 
A partir de 1991, a reunião dos antropólogos do Norte/Nordeste vem acontecendo de maneira bienal e ininterrupta. Oficialmente chamado de Encontro de Antropólogos do Norte/Nordeste, o evento era popularmente conhecido como "Abinha". Contudo, em 2003, na oitava edição realizada em São Luís (MA), foi adotado o nome pelo qual é conhecido atualmente, através da sigla ABANNE, passando a ser chamado oficialmente de Reunião de Antropólogos do Norte/Nordeste, aplicando-se retroativamente a nova nomenclatura para as edições anteriores.

Como se pode ver pelo quadro abaixo, nos primeiros 16 anos de existência da ABANNE (1985-2001), a sua realização se concentrou em 3 estados: PE (4 edições), Pará (2 edições) e PB (1 edição). A partir de 2003, começa a haver uma maior expansão, desconcentração e melhor distribuição entre estados realizadores, não havendo desde então repetição de "sedes".

\section{Quadro 1 - lista das edições da ABANNE e ABANNE/REA}

\begin{tabular}{|c|c|c|c|}
\hline No & EVENTO & CIDADE & INSTITUIÇÃo \\
\hline 1985 & I ABANNE & Recife (PE) & UFPE \\
\hline 1991 & II ABANNE & Recife (PE) & UFPE \\
\hline 1993 & III ABANNE & Belém (PA) & UFPA e Museu Emílio Goeldi \\
\hline 1995 & IV ABANNE & João Pessoa (PB) & UFPB \\
\hline 1997 & V ABANNE & Recife (PE) & UFPE \\
\hline 1999 & VI ABANNE & Belém (PA), & UFPA e Museu Emílio Goeldi \\
\hline 2001 & VII ABANNE & Recife (PE), & UFPE \\
\hline 2003 & VIII ABANNE & São Luís (MA) & UFMA \\
\hline 2005 & IX ABANNE & Manaus (AM) e Boa Vista (RR) & UFRR e UFAM \\
\hline 2007 & X ABANNE/I REA & Aracaju (SE) & UFSE \\
\hline 2009 & XI ABANNE/II REA & Natal (RN) & UFRN \\
\hline 2011 & XII ABANNE/ III REA & Boa Vista (RR) & UFRR \\
\hline 2013 & XIII ABANNE/ IV REA & Fortaleza (CE) & UFC \\
\hline 2015 & XIV ABANNE/VREA & Maceió (AL) & UFAL e UNIT \\
\hline
\end{tabular}

Fonte: Edições de 1985 -2003, em Motta et al (2004); Edições de 2005 -2015 - fontes orais

Pode-se dizer que essa diversificação acompanhou as políticas de expansão das universidades (graduação e pós-graduação) e da desconcentração regional dos investimentos em educação e pesquisa. Assim, parte desta diversificação se deve a criação de vagas de trabalho para profissionais de antropologia nas diferentes províncias das duas regiões, sobretudo, entre outras coisas, através da criação de cursos de pós-graduação em antropologia e de departamentos de antropologia ${ }^{10}$. Por outro lado, é a realização da reunião

\footnotetext{
${ }^{10}$ A próxima ABANNE/REA será realizada em Teresina/PI. Assim, entre os estados do N/NE com pósgraduação em Antropologia, quem nunca sediou o evento é apenas o estado da Bahia. Os demais estados que ainda não receberam o evento, são da região Norte: Acre, Amapá, Rondônia e Tocantins.
} 
em estados sem cursos de antropologia (em nível de pós-graduação) que parece contribuir para consolidar o esforço já existente de implantar um projeto de criação de um programa de pós-graduação em antropologia, a exemplo do que ocorreu na UFRR, que realizou a ABANNE/REA em 2011, e cujo mestrado começou a funcionar em 2016; e na UFC, que realizou a ABANNE/REA em 2013, em processo de elaboração/submissão da sua proposta à Capes. Como explicita o relatório de prestação de contas da Comissão Organizadora da ABANNE/REA 2015 (Maceió-AL):

"No que tange especificamente a contribuição do evento na implantação do curso de Mestrado em Antropologia Social da Ufal, destacamos especialmente a contribuição dos conferencistas para as atividades dos grupos de pesquisa que constituem o PPGAS e a prospecção de possibilidades de intercâmbio e cooperação com grupos consolidados nacional e internacionalmente."(Nessa edição, Meinerz, Mura e Souza, 2016, p.112)

Através da avaliação realizada pela Comissão da ABANNE/REA 2015, é possível ainda confirmar um segundo impacto importante (na realidade complementar ao anterior): "A realização do evento na cidade de Maceió contribuiu para a consolidação da área da Antropologia nas regiões Norte e Nordeste, contexto em que se concentram os principais esforços de expansão da disciplina, tanto no que concerne à integração de novos cursos ao conjunto da Antropologia Вrasileira quanto à ampliação das redes de cooperação internacional" complementando que

"[...]destacamos a visibilidade da produção acadêmica dos profissionais do estado de Alagoas. A repercussão dos congressos, torna-se um incentivo tanto à produção dos docentes e discentes do recém criado curso de pós-graduação em Antropologia, quanto à reflexão sobre as assimetrias existentes na distribuição de recursos e sobre a desigualdade nos espaços de atuação entre os Programas de Pós-Graduação das diversas regiões do país. Nesses termos, destacamos a importância política da realização dos congressos, visando a concreta integração das produções antropológicas dessas regiões no conjunto da Antropologia Brasileira." (Meinerz, Mura e Souza, 2016, p.111-112)

A consequência lógica que se tira é a de que a realização de tal evento possibilita e/ou contribui para a consolidação das antropologias locais, visibilização da sua produção e, ainda, fortalecimento da área dentro das instituições locais.

No percurso da ABANNE, alguns momentos se configuram como marcadores dos diferentes movimentos e direções tomados pelo evento. O primeiro deles, em 1985 com a sua "fundação"; o segundo, em 1991, com a sua "retomada", criando as condições para a sua continuidade, em que nos anos posteriores consolida-se como evento regional e inicia a sua transformação em evento de alcance nacional; o terceiro, em 2003, com a mudança definitiva do nome para ABANNE, marcando ainda a etapa de consolidação, expansão geométrica (em termos de participação, organização e estrutura) e confirmação de seu status de evento nacional; o quarto, em 2007, com a agregação à ABANNE da Reunião Equatorial de Antropologia (REA), de caráter internacional. 
A criação da REA vem, em certa medida, atender às expectativas e exigências de internacionalização, implementadas pelas diferentes políticas da CAPES/MEC, em seus processos de avaliação, legitimação e consequentemente, distribuição de recursos. Por outro lado, transformar a ABANNE em REIA teve como inspiração o sucesso da Reunião de Antropólogos do Mercosul (RAM) ${ }^{11}$, organizada e gerida pelas províncias do Sul e pelos antropólogos da Argentina, Chile e Uruguai. Nesse sentido, a REA implicaria em adotar o mesmo modelo da RAM, e seria gerida pelo consórcio de países equatoriais (em princípio aqueles da América do Sul), circulando a realização do evento entre os seus "sócios". O projeto de transformar a ABANNE em REA deve-se a Carlos Caroso (UFBA), então presidente da ABA (2006-2008). A proposta ia em duas direções diferentes: de um lado, iniciar o processo de maneira não "traumática", ou seja, agregar o nome de REA ao da ABANNE, que permaneceria, mas paulatinamente esvaziar o sentido da última e, em duas ou três edições, substituir completamente ABANNE por REA. Por outro lado, propunha realizar um acordo com a RBA, RAM e REA, para transformar as edições destas reuniões de bienal para trienal, procurando evitar concorrência e também dar maior racionalidade para a organização e esforços despendidos para a realização dos encontros.

Esta última proposta, de organizar os três maiores eventos de antropologia na América do Sul a partir da lógica trienal, distribuindo cada evento em um ano diferente, em que pese a sua lógica racional e mesmo de integração - em especial, por que daria maior fôlego e tempo para as diferentes comissões na organização desses eventos (especialmente capitação de recursos), encontrou uma barreira intransponível: a negativa dos grupos de antropólogos dos países que compõem a organização e gerência da RAM. Suponho que um dos argumentos contrários às edições trienais se baseie no fato de que, se isto faz sentido para a antropologia brasileira escalonar seus três grandes eventos (RBA, RAM, ABANNE/REA) em anos diferentes, não se pode dizer que o mesmo valha para as antropologias da Argentina, Chile e Uruguai; outra suposição minha é a de que haveria o medo de perder espaço e poder diante da força da antropologia brasileira, se a RAM se atrelasse à lógica da dinâmica brasileira. Mas, o que é fato, é que os antropólogos desses países se recusam a que a RAM seja sediada em outros estados que não os do Sul brasileiro. Segundo consta, tentativas já foram feitas para que outros estados fora do Sul sediasse o evento, mas sempre se encontrou diante de negativas, dando-se por justificativa que os antropólogos desses países não se deslocariam para outros estados do Brasil, por causa do custo do deslocamento. Ou seja, na realidade, o nome "mercosul" não significa o que parece indicar o nome: países da América do Sul, mas países do sul da América do Sul + o Sul do Brasil.

\footnotetext{
${ }^{11}$ Segundo Teixeira (2006), a primeira RAM ocorreu em 1995, em Porto Alegre (RS).
} 
O segundo eixo do projeto, o de transformar a ABANNE completamente em REA, encontrou resistência entre os antropólogos do Norte e Nordeste, em que talvez uma das vozes mais ativas nesta resistência tenha sido a minha. Desde que ouvi pela primeira vez a proposta, quando ainda atuava na UFBA, em 2006, considerei que ela traria efeitos contrários ao desejado e, sobretudo, implicaria abrir mão do nosso espaço de poder e visibilidade, a duras penas conseguido. Dez anos depois, com um olhar mais maduro, continuo firme na minha posição de resistência em favor da continuidade da ABANNE, mas agora considerando que é possivel manter a articulação entre ABANNE e REA.

Ao fazer este pequeno percurso da memória da $A B A N N E$, pode-se concluir que o seu primeiro objetivo - lançado em 1985 - foi alcançado, tornando-se a ABANNE um dos três mais importantes fóruns de discussão da antropologia nacional, junto com as reuniões da ABA e a RAM, e onde os antropólogos norte/nordestinos conseguem, de maneira considerável, visibilizar sua produção e viabilizar projetos de cooperação entre instituições em nível regional, nacional e internacional. No que se refere ao seu segundo objetivo, de elaborar uma crítica consistente e constante que desconstrua politicamente as relações de dominação geopolítica do campo da antropologia nacional, parece-me que foi pouco eficaz. Considero que, ao longo da sua consolidação, e especialmente a partir da agregação da REA e do projeto de internacionalização, houve uma inflexão da ABANNE de cada vez mais sair da lógica do "espaço político" para abraçar a lógica do "evento", como se o seu sucesso na produção relativa de uma visibilidade por si só tivesse a virtude de transformar as relações de poder, e que, portanto, não seria mais necessária a construção da ABANNE (e da própria ABANNE) como "espaço político". Argumento, contudo, que essa inversão da lógica do "espaço político" pela do "evento" guarda a possibilidade em si mesma de reduzir a pó os sucessos de visibilidade obtidos. É o que discuto a seguir.

\section{QUANDO E COMO SER ABANNE E/OU REA}

\section{[... ]Esses direitos não são permanentes. Você terá que manter- se vigilante durante toda a sua vida. Simone de Beauvoir}

Pôr como epígrafe desta parte uma citação de Simone de Beauvoir pode parecer estranho, mas o estranhamento é apenas aparente. Apesar de ela tratar das relações de dominação de gênero (ou talvez por isso mesmo), a frase cabe bem para se pensar toda e qualquer forma de dominação. Ela serve para criar a consciência que toda e qualquer conquista, todo e qualquer direito - e no caso específico do campo da antropologia brasileira - toda e qualquer visibilidade não é adquirida, nem garantida de forma permanente. No momento em que os dominantes se sentirem mais ameaçados da perda do seu domínio, no momento em que os meios (práticos, financeiros e simbólicos) a serem distribuídos se tornem 
cada vez mais escassos (em especial em momentos de crise e diminuição de recursos econômicos), os direitos e conquistas dos "subalternizados" são ameaçados, e as possibilidades reais de perdê-los são maiores do que aquelas de mantê-los. A luta, portanto, é permanente.

Neste sentido, os espaços de circulação do conhecimento produzido pelos quais nos movimentamos, não são espaços neutros e objetivos, cujo único critério que tem validade é o do mérito e qualidade, em que uma vez alcançado o desejado reconhecimento e visibilidade, não o perderemos mais. Movimentamo-nos, ao contrário, em um campo político, mais especificamente, em um campo geopolítico.

É a partir desde princípio que construo as categorias de "espaço político" e de "evento", que podem agir de maneira complementar ou em oposição. De qualquer forma, a ação dessas/nessas categorias não é ingênua e nem desprovida de intenções políticas. A esta altura, deve parecer óbvio para o leitor que "espaço político" compreende a ideia de um tempo-espaço de atuação em que a crítica, a denúncia, a resistência e a construção de estratégias contra-hegemônicas se instituem, se desenvolvem e se propagam; a ideia de "evento", ao contrário, promove o esvaziamento da crítica, da denúncia, da resistência e da ideia mesmo de que no campo acadêmico outras coisas que o mérito e a qualidade estejam em jogo, desqualificado a denúncia das relações assimétricas entre pesquisadores, instituições e províncias ${ }^{12}$.

Idealmente, a lógica do "evento" parte do principio de que não são as condições histórico-político-estruturais que estabelecem as distinções e as relações assimétricas no campo acadêmico. Ela pressupõe que o esforço, a competência e o sucesso individual ou de um grupo não é uma questão estrutural. No "evento" seria o momento e o lugar em que todos seríamos igualmente ouvidos, todos seríamos igualmente considerados, todos seríamos igualmente visibilizados, na medida da qualidade e competência de cada um. Nesse perspectiva, ao se tomar a ABANNE como "evento", faz sentido expandir o seu escopo de ação e transformá-la em um espaço de internacionalização porque, de um lado aumentaria o seu prestígio, de outro abriria as fronteiras para aumentar ainda mais a visibilidade e a propagação da produção daqueles que tem qualidade.

\footnotetext{
${ }^{12}$ É bom lembrar que estou bastante ciente do fato de que boa parte do campo da antropologia brasileira, independentemente da sua localização, faz a crítica das relações de poder e dominação na sociedade brasileira, faz a crítica à lógica da meritocracia pura. Contudo, tudo se passa como se os acadêmicos em si mesmo estivessem olhando a partir de um ponto exterior à sociedade, como se estivessem dentro de uma redoma de neutralidade, em que estas questões não constituiriam o seu próprio campo de atuação. Sublinho ainda que não sou contrária ao mérito, mas sim que o mérito só pode ser justo, quando se leva em conta ou está relacionado às condições sociais e práticas de sua produção. O mérito nunca é o resultado apenas das qualidades inerentes do sujeito, ele é um produto social.
} 
Se tomarmos a transformação da ABANNE em REA a partir da chave do "evento", nada poderia ser mais lógico do que realizar este objetivo, ainda mais por termos como exemplo a RAM que é bem sucedida. Aliás, é essa a perspectiva adotada pelos centros hegemônicos, e que, portanto, deveríamos acriticamente adotar. Contudo, mesmo do ponto de vista da lógica do "evento" há de se perguntar quais as reais condições práticas da sua realização: em termos de captação de recursos, qual é a capacidade de fato - diante das disputas de verbas dentro das agências financiadoras, que priorizam financiar as instituições do centro-sul, de captar os recursos necessários? Os outros países potencialmente parceiros da REA (p. ex.: Venezuela, Equador, Colômbia, Suriname, Guiana e Guiana Francesa) tem uma antropologia suficientemente desenvolvida e suficientemente organizada/institucionalizada para financiar uma participação numérica expressiva no evento? Em termos de distâncias e custo de deslocamento, pode-se dizer que teríamos as mesmas facilidades dos nossos pares situados no extremo sul da América do Sul?

E a última questão, a mais importante de todas, no meu ponto de vista: estaríamos dispostos, ou mais ainda, seríamos tão ingênuos, de abrir mão do nosso espaço de poder, do nosso "espaço político"? Porque, internacionalizar de fato, nos moldes propostos, é ter que ceder poder aos outros países, podendo-se chegar a ter que ceder poder às outras regiões, já que seria o Brasil e não as regiões Norte e Nordeste que estaria em parceria com os outros países.

É nessa direção que considero ser indispensável pensar a ABANNE como "espaço político". Ao não fazê-lo, estaremos perdendo um espaço de ação e de poder, em que está em nossas mãos a capacidade de decisão, a capacidade de construção de estratégias contrahegemônicas; o espaço legítimo e possível de realizar a crítica e denúncia das relações de dominação, e, sobretudo, dos mecanismos narrativos e estruturais que teimam em nos localizar nas posições periféricas, subalternas e silenciadas do campo acadêmico.

Tomar a ABANNE primeiramente e preponderantemente como "espaço político" é criar as condições legítimas para adotar políticas de "reserva de mercado", políticas que priorizem a nossa lógica de produção de conhecimento, políticas que criem espaços de visibilidade para nossos estudantes, que estão em sua maioria em nível de mestrado. Mesmo se a adoção de políticas específicas de visibilização e crítica não tenham ocorrido de maneira programática, consciente e planejada, é porque a ABANNE adotou estas ações políticas, ao longo de suas edições, que foi possível produzir a nossa visibilização. Ações tais como: a obrigatoriedade de que mesas e GT's sejam coordenados por pelo menos um profissional de instituição do Norte/Nordeste; aceitar a participação de alunos de mestrado/mestres com apresentação oral de trabalhos. Só estas duas ações tem tido um efeito prático enorme nos objetivos de visibilização e empoderamento dos nossos pesquisadores e alunos. Em especial, a ABANNE abre um espaço para mestrandos e mestres, que cada vez mais - nos outros 
congressos - veem suas possibilidades de apresentar seus trabalhos reduzidos ao tempo e espaço de um pôster ${ }^{13}$. Levando em consideração que nas regiões Norte e Nordeste temos apenas cinco cursos de doutorado, ao passo que temos dez cursos de mestrado, a ABANNE como "espaço político" é fundamental para dar visibilidade a estes mestrandos e suas instituições ${ }^{14}$. A tudo isto se soma o papel indutor da ABANNE, já discutido anteriormente, na consolidação, visibilidade e circulação do conhecimento produzido pelas antropologias e antropólogos das províncias que sediam o evento.

Isto dito, escolher entre internacionalizar ou não, não é de fato a questão. A questão é "qual modelo e/ou estratégia de internacionalização se quer adotar para a ABANNE"? Uma que se apoie na lógica do "evento" e, consequentemente, produza um esvaziamento da sua capacidade de colaborar nas lutas políticas dentro do campo geopolítica da antropologia brasileira? Ou uma estratégia que, apoiada na lógica do "espaço político", utilize-se da internacionalização como mais uma ferramenta contra-hegemônica?

Parece-me que o mais inteligente é o de adotar um modelo próprio, que ao mesmo tempo garanta o nosso "espaço político" e também atenda as necessidades de circulação e de cooperação internacional. Curiosamente, seja por inércia, seja pela resistência que recusou a transformação total da ABANNE em REA, seja pelas dificuldades econômicas, criamos um modelo próprio, talvez mesmo híbrido, em que aliamos a lógica do "espaço político" (ABANNE) à lógica do "evento" (REA). Olhando para traz e avaliando a experiência da ABANNE/REA, considero que este é o modelo que melhor faz sentido para as nossas especificidades e necessidades regionais. O que precisaríamos, agora, seria partir para uma nova etapa que implique em uma conscientização da ABANNE/REA como prioritariamente "espaço político", articulada secundariamente como "evento", para tornar de fato esse espaço em momento propício para realizar a crítica às relações de poder no campo geopolítico acadêmico, visando ainda à elaboração de uma contra-narrativa que promova relações mais simétricas nesse campo, ao desconstruir as narrativas hegemônicas que nos desqualificam.

\section{MAIS ALGUMAS PALAVRAS}

Pensar os processos, investimentos e estratégias de internacionalização/internacionalizar, e até onde se deve ir neste processo, não pode ser feito apenas de um ponto de vista puramente qualitativo e/ou quantitativo, porque isto não apenas

\footnotetext{
${ }^{13}$ Por experiência própria sei qual importante é a ABANNE para abrir espaços de visibilização da produção dos mestrandos. Foi em uma ABANNE, naquele tempo ainda chamada de Abinha (a de João Pessoa-PB), que tive a primeira oportunidade de fazer uma apresentação oral.

${ }^{14}$ Cursos de doutorado: UFAM, UFBA, UFPA, UFPE, UFRN. Cursos de mestrado: UFAL, UFAM, UFBA, UFPA, UFPB, UFPE, UFPI, UFRN, UFRR, UFS.
} 
se dá através de parâmetros neutros ou objetivos de qualificação/quantificação/produção/consecução. Estes processos devem ser prioritariamente pensados e analisados "politicamente", porque se inserem no jogo dos interesses (geo)políticos acadêmicos e nas relações de poder - que implicam nas lutas de classificação. É tendo o jogo político como parâmetro que o campo acadêmico e as estratégias de visibilização/qualificação devem levar em conta estratégias políticas de ação, potencializando os instrumentos que tem à mão como ferramentas para atingir melhores posições no campo da geopolítica acadêmica, e especificamente da geopolítica da Antropologia Brasileira.

É diante deste quadro que tenho argumentado que a ABANNE/REA deve ser pensada não apenas como "evento" que promove circulação de informação, mas como "espaço político" e de ação política, cujo objetivo é o de dar visibilidade aos antropólogos e estudantes de antropologia do Norte/Nordeste, assim como o de construir um pensamento crítico, visando à quebra das relações hegemônicas que mantêm a produção destas regiões às margens dos grandes debates, ou seja: silenciada. Neste sentido, o nosso projeto e objetivo deve ser o instrumentalizar a ABANNE/REA para que, enquanto "espaço político", continue contribuindo para a produção de relações mais simétricas no campo da geopolítica acadêmica, ao mesmo tempo em que, enquanto "evento", promova um espaço aberto para troca de saberes e circulações das ideias, numa perspectiva que conjugue a atuação regional, nacional e internacional. 


\section{REFERÊNCIAS BIBLIOGRÁFICAS}

BOURDIEU, Pierre. La distinction : critique sociale du jugement. Paris: Minuit, 1979.

DWYER, Tom. Reflexões sobre a internacionalização da sociologia brasileira. Revista Brasileira de Sociologia - RBS, v. 1, n. 1, p. 57-88, 2013.

FIORIN, José Luiz. Internacionalização da produção científica: a publicação de trabalhos de Ciências Humanas e Sociais em periódicos internacionais. R B P G, v. 4, n. 8, p. 263-281, 2007.

LEAL, Sérgio; HOLANDA, Luciana; SANTANA, Taynon. A internacionalização da pesquisa em Turismo no Brasil. Fórum ABRATUR-15. São Paulo: USP, junho de 2015 (Comunicação oral).

MAUÉS, Heraldo. Antropologia da Amazônia: uma introdução. Revista Anthropológicas, v. 3, n.7, p. 6768, 1998.

MEUCCI, Simone. Prefácio. IN: Freyre, G. (2009[1945]). Sociologia: introdução ao estudo dos seus princípios. São Paulo: Realizações, 2009. p.11-26

MOTTA, Antonio e BRANDÃO, Maria do Carmo. 0 campo da Antropologia e suas margens: pesquisa e sua disseminação em diferentes instituiç̧ões de ensino superior no Nordeste. In: FILHO, W. T. e RIBEIRO, G.L. (Orgs.). 0 campo da antropologia no Brasil.Rio de Janeiro: Contra Capa/ABA, 2004.p.163-186.

MOTTA, Roberto. Um Mestrado de Antropologia em Pernambuco.Revista Anthropologicas, v. 2, p. 15-39, 1997.

MOROSINI, Marília. Internacionalização na produção de conhecimento em IES Brasileiras: cooperação internacional tradicional e cooperação internacional horizontal. Educação em Revista, Abr 2011, v.27, n.1, p.93-112, 2011.

OLIVEIRA, Roberto Cardoso de. Sobre o Pensamento Antropológico. Rio de Janeiro: Tempo Вrasileiro, 1988.

REESINK, Mísia; CAMPOS, Roberta. A geopolítica da antropologia da religião no Brasil, ou como a "província" vem se submetendo ao leito de Procusto. In: SCOTT,P. CAMPOS, R. e PEREIRA, E. (Orgs.). Rumos da antropologia no Brasil e no mundo: geopolíticas disciplinares. Recife: UFPE, 2014. p. 55-81.

prelo) . As Ciências Sociais Brasileiras Frente ao Eurocentrismo: imposição ou escolha? 2016 (no

MEINERZ, Nádia; MURA, Claudia; SOUZA, Jordânia de Araújo. Para além do Relatório: Reflexões sobre a realização de um evento como a V REA e XIV Abanne . Revista Mundaú,n.1, p. 103-118, 2016.

SCOTT, Parry. A antropologia nas franjas da periferia: vinte anos de pós-graduação em Pernambuco. Revista Anthropológicas, v. 2, p. 57-74, 1997.

TEIXEIRA, Sérgio Alves. A antropologia no Rio Grande do Sul. IN: SANTOS, Silvio Coelho dos; HELM, Cecília Maria Vieira; TEIXEIRA, Sérgio Alves(Orgs.). Memória da antropologia no Sul do Brasil. Florianópolis: Editora da UFSC/ABA, 2006, p. 125-204. 